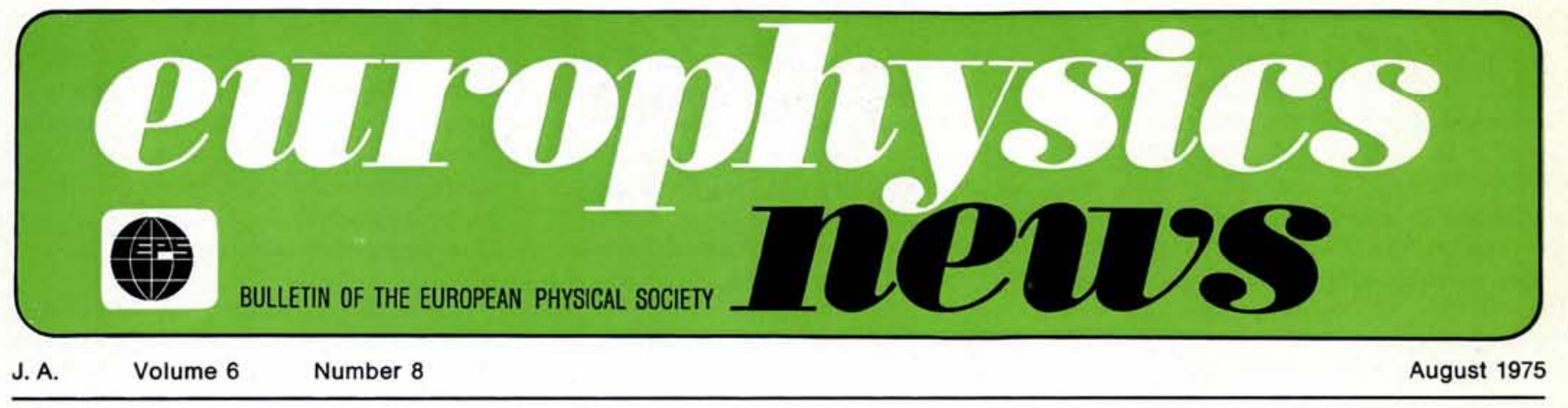

\title{
Physics in Romania
}

During the last years, physics has been intensively developed in Romania, as a result of the continuous encouragement and support given by the government.

The official body called to co-ordinate and to control the entire scientific activity in Romania is the National Council for Science and Technology. The guiding of the physics research and its applications is done by the State Committee for Nuclear Energy, to which answer several research, education and production units.

The main research facilities are concentrated at the National Physics Centre-Magurele, near Bucharest, consisting of the Institute for Atomic Physics, the Institute for Technical Physics, the Centre for Radiochemical Production, the Centre for Nuclear Equipment, the Institute of Physics, the Faculty of Physics of the Bucharest University, the Centre for Postgraduate Education, and the Documentation Office for Physics. The location of all these units on the same site enables a more efficient contact between research, training and production. Thus, the research workers in physics can teach the students in the faculty and the educational staff from the faculty are directly engaged in research and production, using all the facilities of the institutes on the site. It is to be noted also that the National Physics Centre, Bucharest, which has at its disposal a centre for production of modern apparatus and equipment for industry, is able to use directly the main discoveries and progress in the field of applied physics, achieved in this country. The concept of integration of research, teaching and industrial production, which was largely supported by the Romanian authorities, was first introduced at this National Centre of Physics.

Based on the positive results obtained within the framework of this Natio- nal Centre of Physics, it was decided to create other such complexes in other towns of Romania such as ClujNapoca, Pitesti, etc.

There are in Romania other research units, which have a tradition in basic and applied research, like Cluj-Napoca with its Institute of Stable Isotopes and the Faculty of Physics, as well as the Universities of lassy, Timisoara and Craiova. The Institute of Stable Isotopes deals mainly with studies of physical and chemical processes of separation of stable isotopes and elaboration of technologies for their production.

To realize the important goals of the nuclear industry to contribute to the economic and social development of Romania, the State Committee for $\mathrm{Nu}$ clear Energy established other nuclear centres directly connected to the nuclear industry, one of them being the Institute for Nuclear Technology, near Pitesti.

The representatives of all the research institutes in physics, the faculties of physics and university chairs of physics constitute a National Scientific Council, called the Central Institute of Physics. The role of this council is to discuss the main directions of physics research in Romania, to establish plans for the further development of different branches and new directions in physics.

Its main task is to examine continuously how the basic research is used for the needs of applied physics and for the utilization in industry of the new discoveries in physics.

In Romania, physics has been developed on the basis of a solid tradition stemming from the pre-war period when Romanian physicists, like Horia Hulubei, Alexandru Proca, Stefan Procopiu, Eugen Badarau, started research in radioactivity and atomic physics, mathematical physics and theore-

\section{Ursu, Bucharest}

tical physics, magnetism, plasma physics and spectroscopy.

A new stimulus was given to physics in 1949 after the foundation of the Academy Institute of Physics, situated in Magurele.

In 1956, the Institute for Atomic Physics grew out of the Academy Institute of Physics and afterwards the other institutes of the National Centre of Physics were progressively founded. Here, alongside the above-mentioned research branches new specialities were developed, like nuclear and high energy physics, solid state and metal physics, non-linear optics and lasers, physics and technology of reactors, nuclear fuels and materials, moderators, apparatus and equipment for nuclear power plants, etc.

Several large installations such as research and testing reactors, different types of accelerators, and recently a tandem accelerator of the King type have been built here in a short time. Now the National Centre of Physics has at its disposal a variety of equipment and technical supplies, meeting the contemporary research needs, which enables advanced basic research work in such fields as: the fission of mesic atoms, nuclear isomery, analogue resonant states, competitive mechanism of direct and compound nucleus reactions, ESR and

\section{CONTENTS}

Physics in Romania .

Society News

Physics Conferences in Europe-

Highlights on Laser Fusion . . 5

European Study Conference on Multiphoton Processes

7th European Conference on Atomic Spectroscopy

1
2
3
4
5
7
8

Europhysics News is published monthly by the European Physical Society. (C) 1975. Reproduction rights reserved. 
NMR studies on materials, Moessbauer effect studies, stable analytic extrapolation techniques, boundary condition effects on the thermodynamic properties and elementary excitations in partially finite systems, low energy levels of spherical nuclei studied by means of the canonical transformations, inclusive reactions at high energy, etc.

The applied research is represented by the studies of nuclear technologies in connection with the national programme of nuclear energy development, the use of physical methods and nuclear techniques in industry, agriculture, health, biology, the use of isotopes as tracers, in gamma radiography, activation analysis as well as research in semiconductor physics with direct applications in electronics.
The physics activities in Romania are developed also in the general framework of international cooperation. In this sense, Romania cooperates with all other countries in the field of peaceful uses of nuclear energy and physics. This cooperation is promoted through the State Committee for Nuclear Energy, the National Council for Science and Technology, and the Romanian Academy. Through these bodies and institutes, the Romanian scientists maintain and develop broad collaboration with such organizations and institutes as: the International Atomic Energy Agency - Vienna, the Joint Institute for Nuclear Research Dubna, the Institute for High Energy Physics - Serpukhov, the Institute of Theoretical Physics - Trieste, and CERN - Geneva.
All research workers and university teachers in physics in Romania are members of the Romanian National Committee of Physics, which is a national member society of the European Physical Society and also one of the founders of this society.

Romania has been host to several international physics meetings, like the summer school of Mangalia on " Magnetic Resonance and Related Phenomena" and the summer schools of Predeal on "Nuclear Physics", "Boundary Problems Between Nuclear and Solid State Physics", "Nuclear Data and Nuclear Technology ", the Ampere Congress and is now preparing for the third EPS General Conference, to be held in Bucharest on 9-12 September 1975 .

\section{Society News}

\section{Member Societies}

The French Physical Society has reelected Professor I. Solomon as President.

Dr. P. Radvanyi is the new Secretary General.

The Polish Physical Society has awarded the Marian Smoluchowski Medals to Professor G.N. Flerow, Dubna, USSR and Professor G.L. Pearson, Stanford University, USA.

\section{Divisions}

Result of the election of the 12 members of the Board of the Plasma Physics Division, taking office on 1st January 1976 :

\section{T. Consoli, Grenoble}

J.L. Delcroix, Grenoble

J. Dougherty, Cambridge

F. Engelmann, Jutphaas
S. Hamberger, Culham

B. Kadomtsev, Moscow

J. Kistemaker, Amsterdam

B. Lehnert, Stockholm

D. Pfirsch, Garching

R. Sagdeev, Moscow

P. Vandenplas, Brussels

E. Weibel, Lausanne

\section{Session Chairmen for the 3rd EPS General Conference}

Tuesday, 9th Morning

Afternoon

Parallel Sessions

Evening

Wednesday, 10th Morning

Afternoon

Parallel Sessions

Thursday, 11th

Morning

Afternoon

Parallel Sessions

\section{Evening}

Friday, 12th Morning

Afternoon

Parallel Sessions

\begin{tabular}{l|l}
$\begin{array}{l}\text { I. Ursu and S. Eklund } \\
\text { Elementary } \\
\text { Particle Physics }\end{array}$ & $\begin{array}{l}\text { Energy in } \\
\text { Astrophysics } \\
\text { J. Meyer } \\
\text { H.B.G. Casimir }\end{array}$ \\
\begin{tabular}{l|l} 
M. Rees \\
P. Kapitza and C.M. Braams \\
Elementary \\
Particle Physics
\end{tabular} \\
\begin{tabular}{l|l} 
V.P. Sarantzev & Many Body \\
Problems
\end{tabular} \\
\begin{tabular}{l|l} 
W. Häfele and A.M. Prokhorov \\
Energy and \\
Astrophysics
\end{tabular} & $\begin{array}{l}\text { Nuclear } \\
\text { Physics }\end{array}$ \\
$\begin{array}{l}\text { A. Trautmann } \\
\text { J. Volger }\end{array}$ & D.H. Wilkinson \\
$\begin{array}{l}\text { S. Titeica and H.B.G. Casimir } \\
\text { Elementary } \\
\text { Particle Physics }\end{array}$ \\
$\begin{array}{l}\text { Energy in } \\
\text { C. Rubbia }\end{array}$ \\
$\begin{array}{l}\text { Astrophysics } \\
\text { J. Friedel }\end{array}$
\end{tabular}

Many Body Problems

A. Corciovei

A. Corciovei

Materials for Energy Production and Distribution

W.J. Merz

Materials for Energy Production and Distribution D. Wynn Jones

Physics in Education

A. Janner
Transport and L.A.A. Thomas Use of Solar Energy V. Krasnovsky

Nuclear Physics

I. Popescu

Use of

Solar Energy

V. Mercea

Energy Research Strategies

J.J. Went Storage of Energy
Use of Solar Energy

M. Archer

Energy Research Strategies

D. Schumacher

Geophysics

B. Giovannini 